\title{
Market Orientation, Organisational Learning Capabilities and Strategic Competitiveness: An Inquiry into the Causes of Sustain Competitive Success
}

\author{
Amue Gonewa John ${ }^{1}$ \\ ${ }^{1}$ Department of Marketing, University of Port Harcourt, Nigeria \\ Correspondence: Amue Gonewa John, Department of Marketing, University of Port Harcourt, Nigeria. E-mail: \\ amuejohgonewa@yahoo.com
}

Received: November 25, 2013

Accepted: September 15, 2014

Online Published: September 25, 2014

doi:10.5539/ibr.v7n10p179

URL: http://dx.doi.org/10.5539/ibr.v7n10p179

\begin{abstract}
The nature of effective strategic marketing decision making is rooted in the dynamic processes by which firms develop their learning capabilities to acquire knowledge of their markets, reflect on that knowledge and develop the organization capabilities to respond to the strategic challenges faced. It is the organizational learning processes that provide the dynamics within firm, to manage effectively the interplay between the strategies of the firm and the global market environment. This article explores the link between strategic competitiveness and organization learning capabilities. In particular, the authors develop a conceptual model arguing that the effect of learning capabilities on strategic competitiveness is moderated by market orientations. Proposed to guide future research, the authors discuss the Implications for strategic marketing decision making at both the corporate levels and the public policy domains.
\end{abstract}

Keywords: market orientation, capabilities, strategic competitiveness, organizational learning, competitive success

\section{Introduction}

Successful companies maintain their competitive positions in a global marketing environment that is constantly changing and developing, by maintaining a strong marketing oriented perspective towards the market in which they operate. This position marketing orientation to have a significant influence on the ability of companies to compete effectively on global market. It is from this orientation that companies develop a customer focused strategy and build distinctive advantages to their products through a process of adding value either through product innovation or the incorporation of the services into their offering. This allows them to target specific customer and differentiate themselves from competitors in global market. Martins and Bultez (2009), position that superior performance is the result of a customer value based organizational culture, characterized by managers who are, skilled at learning about customer and their changing needs and at managing the innovation process (Stater, 1997). Thus attitude and mind sets are important starting point for the strategic marketing decision process. It is this attitude and mind sets that articulate the marketing orientation of a company, Gilligan and Wilson (2003), posited that the three key elements of a customer value -based philosophy are: a market orientation that gives the highest priority to the profitable creation and maintenance of superior customer value and the use of market information, continuous learning about customer through the development of formal and informal dialogue, and a commitment to innovation that is customer value focused in order to sustain competitive advantage. This innovation may involve the creation of new business within the existing framework or the rejuvenation of existing business that have stagnated. Not minding whether any or all of these is pursued, it is essential that the organization development and reflects a market orientated culture and reinforces this with a commitment to learning. Marketing orientation can be seen from two different perspectives, the cultural end and the information processing perspective (Narver \& Slater, 1991; Slater \& Narver, 1996; Ttult et al., 2002) priorities the behavioral component within a firm and views marketing oriented firms as having; a strong customer competitor orientation and a high level of inter-functional co-operation within the firm Slater and Narver (1996) articulate marketing orientation as the organizational culture that most effectively and effectively creates the necessary behavior to the creation of superior value for buyers and thus continuous superior performance for the business. Such firms focus on customers and competitor based activities and emphasize the 
acquisition, sharing and acting on marketing, intelligence acquired. It is a firms marketing orientation that steers the management of its market information gathering activities such firms endeavour to have highly refined market sensing capabilities, and so are well placed to anticipate changes and friends in the market and thus respond to them by the development of new customer valued capabilities and innovation products and services (Hult et al., 2002). Jaworski and Kohli (1996) view marketing orientation as the organization wide generation of market intelligence pertaining to current and future customer need, dissemination of intelligence across department and organization wide responsiveness to it. In their view, therefore, marketing orientation firms priorities the organization wide generation of market intelligence pertaining to current and future customer needs, disseminate the intelligence across departments ( $\mathrm{R}$ and $\mathrm{D}$ management finance) and organize wide responsiveness to it selected markets, products that cater for current and anticipated customer needs, Jaworski and Kohli therefore focus on the activities that underpin the generation and dissemination of market intelligence. They also maintain that marketing orientation appears to be facilitated by the amount of emphasis top managers place on it, through continual reminders to employees that it is critical for them to sensitive to market developments. Morgan et al. (1998) likewise take an information system view of marketing orientation. They suggest marketing orientation is the mechanism for the information processing activities of the firm. This is similar to the view of day (1994), who defines marketing orientation as the complex bundles of skills and collective learning exercised through organizational processes, that ensure superior co-ordination of functional activities, like morgan et al. (1998) day argued that market orientation was an outcome of learning, and proposed that organization became more market oriented by identifying and building the special capabilities that set market -driven organizations apart (day, 1994). In their view, therefore, the scope of market orientation goes beyond customers and incorporates competitors. It involves the understanding of customer needs in a manager that allows superior value to be provided; and integrating the effort of the organization resource towards creating superior value of customers.

Firms with positive marketing orientated value have the capacity to understand the need of customer in a manner that allows superior value to be provided, because the firm is geared towards the market it is aware of both existing and potential competitor activities and so is able to identify potential opportunities and threats. As they are organized with the emphasis on achieving competitive advantage, they are able to marshal the firms resources towards creating superior value for customer. Thus marketing oriented firms are seen to be innovative, to have a strong customer focus, to make decision with reference to competitor activities, to have an integrated marketing approach and most of all to be able to deliver a high level of share holderlowner value.

In the next section, we assess the place of market orientation in the marketing literature. Then, we explore market orientation as a platform for organizational learning capabilities we also shed light on how this learning capabilities in the organization resulted in sustainable competitive success. Finally, on the basis of the argument set forth we develop responses to some marketing orientations perennial critics. The study contributes to marketing knowledge in two main ways; first, drawing on organizational learning capabilities and strategic competitiveness, it develops theoretical argument linking marketing orientation and sustain competitive success. Second, the study provides a basis for addressing critics of marketing orientation. Hence, the purpose of the study is to explore the extent of the relationship between organizational learning capability and competitiveness and also to assess the moderating effects of market orientation on the influence of organizational learning capability and strategic competitiveness of the firms.

\section{Theoretical Foundation}

Organizational learning is the ability of organization to share experience and lessons across departments and its outside partners (suppliers, distributors, customers) to enable the learning to be stored in the organizational memory of the entire firms (Doole \& Lowe, 2005). Organizational learning can be defined by studying the concrete structural and procedural arrangements through which actions by member's arrangement through which actions by members that are understood to entail learning are followed by observable changes in the organization's pattern of activities (Cook \& Yanow, 1993 cited in Patterson, 2008). It is this mechanism that become the foundation to understand what organizational learning is, that is the structure, strategies and procedures that allow the organization and its members to learn (Popper and Lipshitz, 1998 cited in Sameulson, 2007). Lambert and Celilgn (2009) posit that, organization do pass through the processes of learning like the individuals but that organization learn when they purposefully adopt structures and strategies to encourage learning. Goh and Ryan (2002) summarized by saying that, the concrete observable organizational system or institutionalized structural and procedural arrangements that describe the concept of a learning organization.

Studies conducted by previous scholars (Goh \& Ryan, 2002; Basil \& Katoz, 2005; Alexander, 2008; Chukwu \& Tygris, 2009). Collaborated that the structures, strategies and procedures adopted that form the basis for a 
learning organization. We therefore need to identify what these mechanisms are that organizations use to enhance learning. Goh and Ryan (2002) suggest that, it is these mechanisms (procedure, structure and strategies) that support learning. It is the present of these mechanism that we define as organizational learning capability. Doole and Lowe (2005) argued that only firms that build these organizational learning capabilities that are able to sustain their competitiveness in the market place. It is the firms that develop the learning capability that are able to reshape themselves and so sustain their competitiveness. Morgan et al. (1998) cited in Davidson (2006) suggest that organizational learning capabilities help firm sustain a competitive advantage over the long term in two ways: by minimizing the incidence and potential impact of serious environmental disturbance, through advance acquisition of knowledge and by the flexibility built through organizational learning which enables the firm to develop rapid company responses in order to exploit emerging opportunities or extinguish threats.

\subsection{Propositions from the Strategic Capabilities of a Learning Organization}

Literature suggests commonalities among the various descriptions in previous studies (Goh, 1998; Goh \& Richards, 1997), we conceptualized five dimensions of capabilities of a learning organization.

\subsubsection{Shared Vision}

Goh and Ryan (2002), posit that organization as a whole, and each unit within it need to have a clearly articulated purpose. The organization members are to be motivated to learn the need to share in the foundation for proactive learning. It provides direction and a focus for learning that fosters energy, commitment and purpose among organizational members (Doole \& Lowe, 2005). Slater and Narver (1996) cited in Ogolish (2006) view the motivating vision as grounded in a sound understanding of the market guiding the business competitive advantage efforts been communicated continuously throughout the organization. Hamel and Prahalad (1994) cited in Kojoh (2007) prefer the term foresight, which they consider to be based on deep insights into the trends in technology, demographics, regulations and lifestyles that can be harnessed to rewrite industry rule and create new competitive space.

Karahanna and Davidson (2009), argued that a clear foresight shared by the staff and management of the firm is fundamental basis for effective strategic decisions and this gives the firms the strategic direction to superior competitive position in global markets which moves beyond the short term view of the firm' current market and is an outcome of the marketing oriented values of the firm. The clear strategic direction gives evidence to employees of the commitment from top management to growth and development. It therefore gives focus to the efforts to build a knowledge capability within the organization (Doole \& Lowe, 2005). We make the following proposition:

P1: Employees and other stakeholders sharing in the common direction, the organization is taking will significantly influence the strategic competitiveness of the firm.

\subsubsection{Leadership Commitment and Empowerment}

Organization leaders need to be committed, the formulation of a core ideology for a company has implications for the role of the executive team responsible for making strategic decisions in terms of the leadership it offers (Doole \& Lowe, 2005). Grant (2002) cited in Amos and Tigris (2010) has argued that if a strong core ideology is to be developed which unifies and motivates the members of the organization, the responsibilities of the executives are to clarify the shared vision and core values of the organization. They further argued that, the leaders should develop alignment between the different business functional areas and promote the understanding and interpretation of information within the context of the organizations' shared vision. Grant then goes on to suggest that organizations leaders need emotional intelligence if they are to have the skills that such a role requires. Bartex (2011), posit that leaders should push responsibility and autonomy from decision making down the line to product managers and venture teams. Peters (2003) suggests companies need to be quick and daring and even a little weird and mad in their innovative thinking. Again, Pius and Anderson (2009) argued that leaders through personal example and involvement, indoctrinate their organizations to accept and adhere to these core values that are essential to the organization's identity and success. They suggest that it is the responsibility of the leadership to retain and sustain the entrepreneurial spirit throughout the company. Thus, Doyle (2000) cited in Pius and Anderson (2009) conclude that strategic decision needs to foster an environment where the strategy making is an evolutionary development that is responsive to market challenges, through a proactive/reactive strategic orientation and a core purpose that is balanced with market orientation. Doole and Lowe (2005) summarized that the strategy constant evaluation and re-evaluation and customer focused strategies are developed which are highly differentiated from those of competitors through innovation and value added mechanisms. We therefore proposed as follows. 
P2: The type of leadership the executive team in the organization offer to their employees and other stakeholders will significantly influence strategic competitiveness of the firm.

\subsubsection{Experimenting and Reward Culture}

Alegre and Chiva (2009), posit that experimentation is one of the essential facilitating factors of organizational learning and that it can be defined as the degree to which new ideas and suggestions are attended to and dealt with sympathetically. Experimentation is the most heavily supported dimension in the organizational learning literature (Hedberg, 1981; Nevis et al., 1995; Tannemhaum, 1997 cited in Wilcoxson, 2007). Nevis et al. (1995) cited in Mannson (2006) considered that experimentation involves trying out new ideas, being curious about how things work, or carrying out changes in work processes. Goh and Ryan (2002) argued that problems faced by the organization present opportunities for experimentation. The organization's structure and systems needs to support this initiative. Budgeting systems, for example, can be designed to challenge the need for doing things because "we have always done them" and compensation systems can be designed to reward innovation and risk taking.

Risk taking can be understood as the tolerance of ambiguity, uncertainty and errors. Sitkin (1996) cited in Bannadus (2005) goes as far as to state that failure is an essential requirement for effective organizational learning, and to this end, examines the advantages and disadvantages of success and errors. Amosi and Pythason (2010) conclude that experimentation is by far the most consistent managerial practice that is observed in learning organizations. The freedom to experiment with new work methods and innovative processes are encourage and supported (Senge, 1990; Garum, 1993; McGgill, Slocum \& Lei, 1993). We can make the following proposition.

P3: Experimenting and rewarding culture in the organization will significantly influence competitive positioning of firm.

\subsubsection{Ability to Transfer Knowledge}

Doole and Lowe (2005), argues that intra-organizational knowledge sharing is a very important measure of organizational learning capability. Knowledge sharing refers to the sharing or transfer of collective knowledge and routine related to the spread of learning amongst the different departments in the organization and their extended partners. Macus and Jelly (2009), posit that organizational learning cannot really occur unless the company has an effective and efficient system for sharing and transferring information. The information needs to be clear, fast and focused (Goh \& Ryan, 2002). Information should cut across-functional and sub-unit boundaries within the organization. McGill and Mayer (2006) posit that the type of information's acquired and distributed should relate to organizational problems and opportunities. This is also supported by majority of previous writers, especially the ability of the organization to transfer knowledge from the external environment for example suppliers distributors, customers and even from benchmarking of competitors (Garvin, 1993; Shaw \& Perkins, 1991).

A good example is Marybest company they once specialized on wine bar for its customers and later the customer asked the company to also serve food delicacies to its line of business. Marybest developed complete hotel system that offered its customers more superior value. This add to the fact that customers needed to be involved in the design process, other stakeholders should also be brought in. intra-organizational knowledge sharing is not simply the ability of an organization to obtain its information from various departments and partners but its ability to share experience and lessons across departments and partners, so enabling the learning to be stored in the organizational memory of the entire organization (Doole \& lowe, 2005).

In today's complex world, individuals need to help each other accomplish organizational objectives. Teams need to have the ability to work cross-functionally. By working together, knowledge can be shared among organizational members and there is also a better understanding of other individuals, their needs and how they work in different parts of the organizations, encouraging knowledge transfer as well (Seng, 1990; 1992; Garvin, 1993). We therefore propose as follows:

P4: Intra-organizational knowledge sharing will significantly influence the strategic competitiveness of the organization.

\subsubsection{Market Orientation - Platform for Leveraging Organizational Learning}

Doole and Lowe (2005), posit that successful companies maintain their competitive position is a global marketing environment that is constantly changing and developing by maintaining a strong marketing orientated culture serve as a platform for leveraging organizational learning, therefore market orientation has a significant influence on organizational learning capability and competitive positioning of the firm. Several studies has 
argued that market orientation develop a customer focused strategy and build distinctive advantages to their products through innovation or the incorporation of key services into their offering (Narver \& Slater, 1991; 1996; Hult et al., 2002). Slater and Narver (1996) cited in Tenebonnet and Stavink (2006) articulated market orientation as the organizational culture that most effectively and efficiently creates the necessary behavior to the creation of superior value for customers and business. Such firms focus on customer and competitor based activities and emphasizes the acquisition, sharing and acting on the marketing intelligence acquired. It is the marketing orientation that serve as a platform that steers the management of its market information gathering activities. Such firms are example of learning organization that has a high refined market sensing capabilities and so are well placed in anticipated changes and trends in the market and thus respond to them by the development of new customer valued capabilities and innovative products and services (Hult et al., 2002). Lambin (2000) cited in Benitta (2007) posit that market oriented firms are seen to be innovative, to have a strong customer focus, to make decisions with reference to competitor activities, to have an integrated marketing approach and most of all to be able to deliver a high level of owner value.

Market oriented firms are able to build the following internal capabilities - organizational management with customer oriented value and belief, inter-departmental dynamics and connectedness, well organized structures and processes for the gathering and dissemination of information and departmentalization as well as cross-functional communication (Lambin, 2000; Benitta, 2007; Mbanas, 2009). We therefore advance the following proposition:

P5: Proactive market orientation moderates the effects of organizational learning capability on strategic competitiveness of the firm.

P6: Responsive market orientation moderates the influence of organizational learning capability on strategic competitiveness.

In this work, we respond to a need for linking the concept of organizational learning capability to strategic competitive position of the firm. We also examine whether other organizational factors such as market orientation can moderate the influence of organizational learning capability on strategic competitiveness. The basic conceptual model showing the relationship is shown in figure 1.

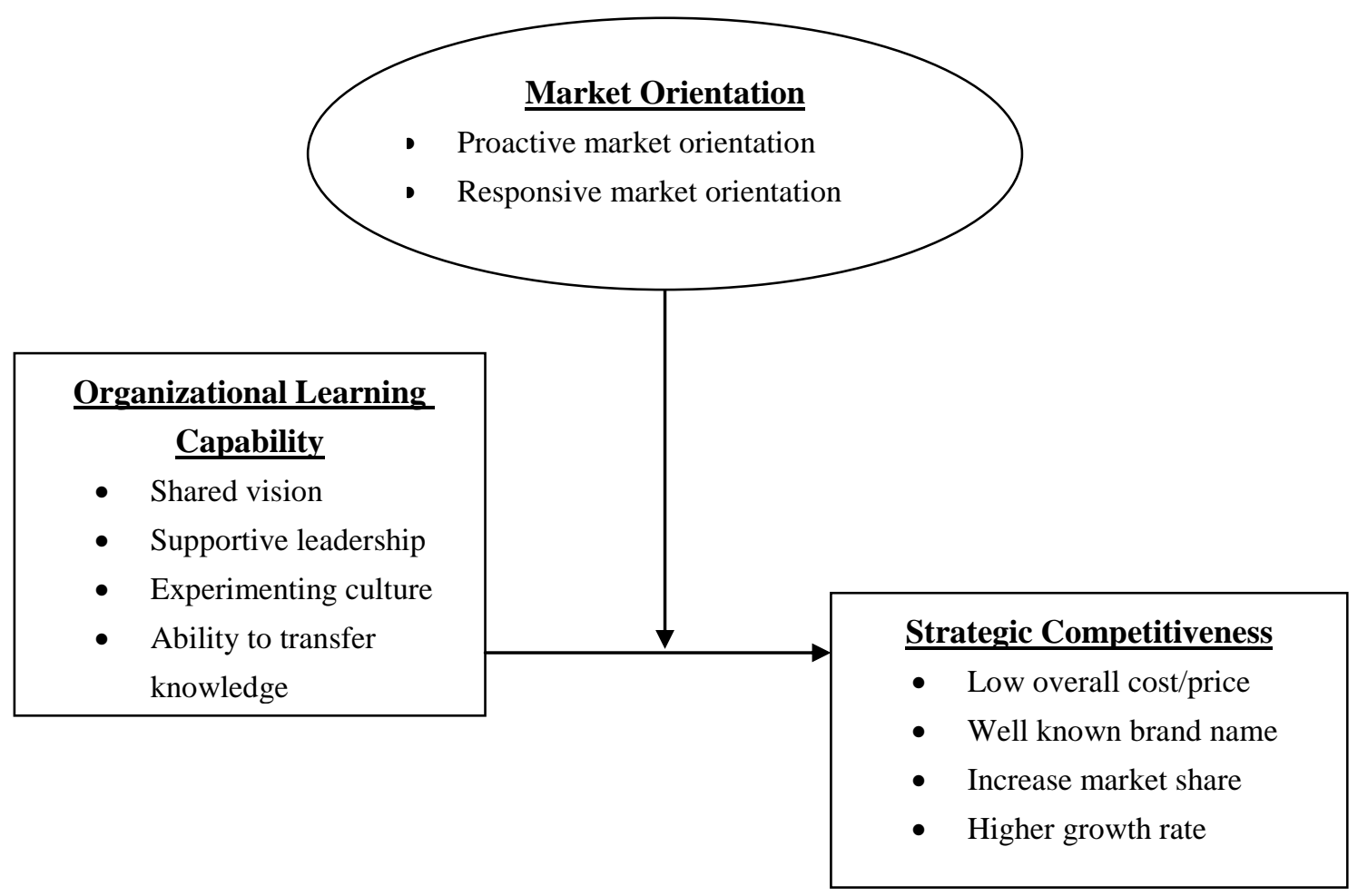

Figure 1. Conceptual model of organizational learning capability, market orientation and strategic competitiveness 


\section{Discussion and Conclusions}

Organizational managers around the globe are recognizing the increasing necessity for their companies to develop the skills, aptitudes and knowledge to compete effectively in global markets. The emergence of a more open world economy, the technological and globalized consumer tastes and the unabated construction of global electronic highways all increase the inter-dependency and interconnections of nation economics across the globe. The marketplace is becoming increasingly complex, as mature economics become more saturated and fragmented the competitive pressure increase and survival and growth become more difficult to sustain. The need for managers to develop the skills to respond to these pressures affects companies of all sizes. It is only a learning organization that can survive this turbulent period.

Several proposed theoretical frameworks underpin organizational learning capabilities that will sustain our competitive position in the marketplace. However, only few of them offer a thorough explanatory and predictive constructs that influence learning capabilities it was proposed that shared vision significantly influence strategic competitiveness of the firm. By competitiveness we refer to those activities that enables the company to remain in business not minding the activities of other competitors in the market for example the establishment of a well known brand name, wider geographic market coverage, low overall costs etc. the question is that, are there any relationship between shared vision as a measure of organizational learning capability and establishment of well known brand, wider market coverage, low overall cost, wider product line and market share leadership? The higher management needs to communicate a well crafted vision for the organization and personally motivate and instill a learning orientation. Without a shared vision employees may be motivated to learn but they may not know what to learn (Johnbull, 2008). Vision co-ordinates the focus of the various departments and encourage employees to overcome cross functional communication barriers and ensure the free flow of information between them, this will reduce cost of running the organization which will in turn lower the overall cost. From this argument, we can deduce that learning capability significantly influence a firm competitive position, in terms of cost reduction.

We also proposed that, the type of leadership the top management offer to their employees and other stakeholders will significantly influence strategic competitiveness. The tentative conclusions suggest that the relationship between learning capability measure as leadership commitment and reward has a significant influence on some measures of strategic competitiveness such as employee morale. When we build leadership supports to our employees this will have a significant influence on their performance if it reduces turn over and absenteeism in organization. Again, hands-on value-driven, refers to the way that leaders serves by example by their personal involvement and retaining the entrepreneurial spirit throughout the organization. By doing this, they have established aa well known identity for the firm.

This behavior will metamorphors into its brand name. Therefore, the type of leadership support has a significant influence on strategic competitive position of the firm. However, leadership support may not be evident in some measure of strategic competitiveness (Micah, 2007). We are aware that competitiveness can be measured in financial and also in marketing terms. When an organization has a supportive leadership as a measure of learning capability this will enhance higher growth rate (sales, revenue) than competitors and the market as a whole.

Again, ability to transfer knowledge within and outside stakeholders will reduce cost of operations which will enhance a higher market share measured in either value or volume terms. Slater and Narver (1996) cited in Adazeh (2007) argued that market orientation moderate the impact of organizational learning capability on competitiveness. As a matter of fact, we expect that organization learning capability affect strategic competitiveness. A major venue for understanding the impact of learning capabilities has been the conditions or situations in the firm. Examination of the alignment of firm structure, strategies and capability for competitive position has provided important theoretical insights (Vorhies \& Morgan, 2003 cited in Amosen, 2006). Because firm conditions provide a platform for the use of learning capability, we suggest that the market orientation provides a critical backdrop for organizational learning capability to come into play.

We proposed that proactive market orientation moderating the effect of organizational learning capability on competitive position of the firm. Proactive market orientation focuses on understanding, anticipating and satisfying customers' latent needs. Organizations often meet latent needs by offering technological advances that enables them to lead the customer to new and better value propositions and satisfaction. This situation enhances the development of learning capability that will enable the firm to be probing into the latent needs of the customers. It is this orientation that moderate the effect of organizational learning on firm competitive position. We therefore argue that firms with proactive market orientations tend to draw heavily on organization learning capabilities to implement strategies that are focused on anticipating and meeting latent needs. 
We argue that firms with responsive market orientation listen to their customers, monitor their competitor, and devise strategies to meet customer needs better than competitors do (Narver et al., 2000, cited in Nwachukwu 2009). Responsive market orientated firms heavily access and extensively rely on their organizational learning capabilities. Because, it is this capabilities that provide the tools and techniques to bring in on customers and to collect timely information that can be used to implement strategies effectively. The role of organizational learning capabilities and their influence on competitive positioning are greater in firms that have responsive market orientation than in those that do not.

From the above, market orientation is very good platform for leveraging organizational learning capabilities.

\section{Implications}

The contributions of this paper attract both conceptual and operational implications to our growing expectation in marketing domain. This paper provides decision makers in organizations with broader bases for making better lasting decisions in the global market place. We are aware that firm competes by building superior values through clearly differentiating their products from competitors or by focusing on one particular market segment and competing by adding value to the product through customer support. Organizations that have a continuous learning capability about customer value that can sustain competitive advantage stand to be a winning organization.

We believe that our work makes the following contributions to the growing literature on both organizational learning capabilities and competitive position of the firm. Figure 1 shows the constructs of learning capability which in this present study we conceptualize as four dimensions of learning capabilities we used the review of related literatures and interactions to contribute new theoretical insights. Again our notion of investigating strategic competitiveness from organization learning capabilities perspectives brings forth the theoretical insight of the resource base view of the firm, our conceptual model, thus explicitly links organizational learning capability to competitiveness. Finally, we replaced the popular moderating variable of organizational factors (age, size, structure) with market orientation as a platform for leveraging learning in organizations.

Future studies are stimulated to improve on the above constructs of the model suggested by this paper. Organizations should be willing to critically evaluate its practices and processes and should be open to new ideas and knowledge. This paper encourage other researchers to proactively question long held routines, assumptions and beliefs, to engage in the first phase of learning which is at the heart of ensuring the firm is aligned to a changing market environment (Doole \& Lowe, 2005) and above all firms are only able to sustain their competitiveness by understanding customer needs in a manner that allows superior value to be provided and it is only by being aware of both existing and potential competitor activities that firms are in a position to take appropriate action to respond to identified opportunities and threats.

\section{References}

Adaezeh, S. T. (2007). Developing Learning Organization: The Behavioral Perspectives. Academy of Management Sciences, 280-290.

Alegre, M. C., \& Chiva, B. S. (2009). The Factory as Learning Store. Academy of Management Review, 28-36.

Alexander, P. P. (2008). Market Orientation and Organization and Organizational Performance: is Innovation a Missing link? Journal of Industrial Marketing, 63(5), 30-42.

Amosi, K. T., \& Pythason, C. O. (2010). Graping the Learning. Organizational Culture: Training and Development, 48(6), 40-46.

Anderson, A. B. (2009). Organizational Learning Capability-Strategy for Competitive Advantage. International Journal of Business and Management, 46(2), 26-39.

Bartex, C. K. (2011). Value Based Learning: Strategy for Corporate Growth and Shareholder Value. Chichester Willey.

Benitta, T. S. (2007). The Impact of Market Orientation, Product Advantage, and Launch Proficiency on New Product Performance. Journal of Product Innovation Management, 21(2), 79-95.

Cook, Y. S., \& Yanow, B. D. (1993). The New Strategic Learning Capability in the Twenty-first Century. The Academy of Management Sciences Review, 25(3), 8-23.

Day, G. S. (1994). The Capabilities of Market-Driven Organizations. Journal of Marketing, 58(Oct.), 37-52. http://dx.doi.org/10.2307/1251915

Doole, I., \& Lowe, R. (2005). Strategic Marketing Decisions in Global Markets. London: Thomson Learning. 
Goh, S. C., \& Ryan. (2002). Organizational Learning Capabilities. European Management Journal, 15(5), 575-583. http://dx.doi.org/10.1016/S0263-2373(97)00036-4

Hult, G. T., \& Ketchem, D. J. (2002). A Test of the Relationship between Positional Advantage and Performance. Strategic Management Journal, 26, 889-906.

Karahanna, B. T., \& Davidson, A. O. (2009). Competitiveness in the Organization: The Possible way out. European Journal of Marketing Science, 21(3), 46-59.

Lambert, P. S., \& Celign, D. E. (2009). The Implementation of Marketing Oriented Culture in Organization. European Journal of Marketing, 42(11), 1265-1295.

Morgan, R. E., \& Strong, C. A. (1998). Market Orientation and Dimensions of Strategic Orientation. European Journal of Marketing, 32(11/12), 1051-1073. http://dx.doi.org/10.1108/03090569810243712

Narver, J. C., \& Slater, B. R. (1991). The effect of a Market Orientation on Business Profitability. Journal of Marketing, 54(4), 20-35. http://dx.doi.org/10.2307/1251757

Patterson, K. K. (2008). Competitiveness: Strategy for Winning Firms. Journal of Management and Behavioral Sciences, 20(4), 58-68.

Pius, S. T., \& Anderson, G. H. (2009). A Learning Organization is a Winning Organization. International Journal of Business and Behavioral Sciences, 24(6), 88-102.

Slater, S. F., \& Narver, J. C. (1996). Market Orientation and the Learning Organization. Journal of Marketing, 59(3), 63-74. http://dx.doi.org/10.2307/1252120

Wilconxson, B. Y. (2007). does market orientation moderate organizational learning capabilities on strategic competiveness? Journal of Behavior Science Research, 56(5), 21-33.

\section{Copyrights}

Copyright for this article is retained by the author(s), with first publication rights granted to the journal.

This is an open-access article distributed under the terms and conditions of the Creative Commons Attribution license (http://creativecommons.org/licenses/by/3.0/). 